\title{
Fullerol-facilitated transport of copper ions in water-saturated porous media: Influencing factors and mechanism
}

\author{
Yue Yuan ${ }^{a, b, c, d}$, Xianjia Peng ${ }^{a, b, c, *}$ \\ a National Engineering Laboratory for Industrial Wastewater Treatment, Research Center for Eco-Environmental Sciences, Chinese Academy of Sciences, \\ Beijing 100085, China \\ ${ }^{\mathrm{b}}$ Beijing Key Laboratory of Industrial Wastewater Treatment and Resource Recovery, Research Center for Eco-Environmental Sciences, Chinese Academy of \\ Sciences, Beijing 100085, China \\ ' University of Chinese Academy of Sciences, Beijing 100049, China \\ d Sino-Danish Center for Education and Research, Beijing, 100190, China
}

\section{H I G H L I G H T S}

- $\mathrm{C}_{60}(\mathrm{OH})_{\mathrm{n}}$ could facilitate the transport of $\mathrm{Cu}^{2+}$ in water-saturated porous media.

- The facilitated transport of $\mathrm{Cu}^{2+}$ was affected by $\mathrm{pH}$ and $\mathrm{C}_{60}(\mathrm{OH})_{\mathrm{n}}$ concentration.

- The presence of $\mathrm{C}_{60}(\mathrm{OH})_{n}$ decreased the retention factor of $\mathrm{Cu}^{2+}$.

- The facilitation was mainly due to the higher adsorption of $\mathrm{Cu}^{2+}$ by $\mathrm{C}_{60}(\mathrm{OH})_{\mathrm{n}}$.

\section{A R T I C L E I N F O}

\section{Article history:}

Received 16 March 2017

Received in revised form 17 June 2017

Accepted 1 July 2017

Available online 3 July 2017

\section{Keywords:}

Facilitated transport

Copper ions

Fullerol nanoparticles

Porous media
G R A P H I C A L A B S T R A C T

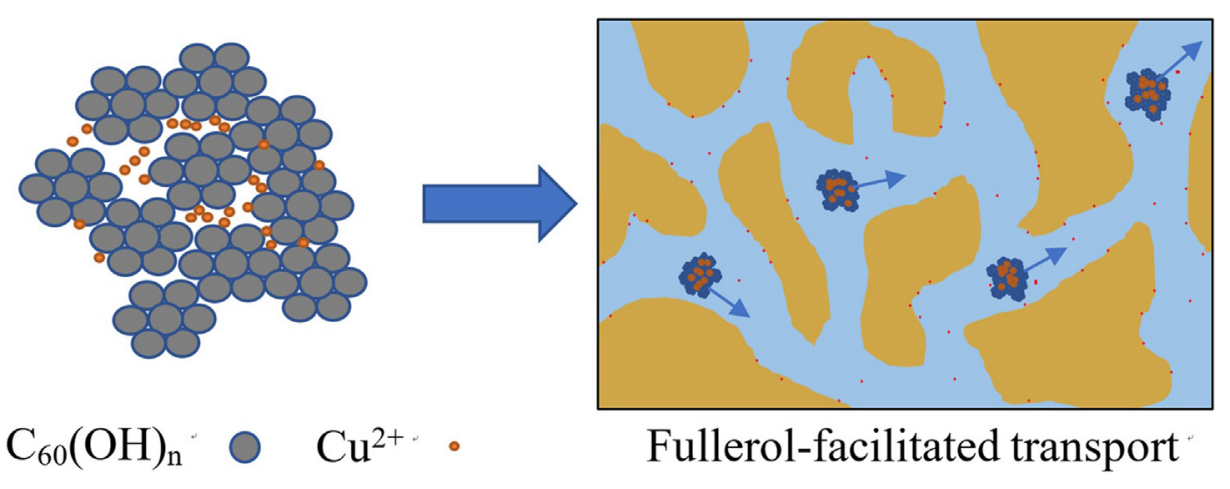

\begin{abstract}
A B S T R A C T
The environmental safety of carbon nanomaterials (CNMs) has become a hot spot of worldwide research work. The high stability, mobility and adsorption capability of CNMs may give rise to the enhancement of heavy metal transport. However, the understanding of facilitated transport of heavy metal ions by CNMs is still limited. In this research, fullerol nanoparticles $\left(\mathrm{C}_{60}(\mathrm{OH})_{\mathrm{n}}\right)$ were used as a typical CNM to investigate its effect on $\mathrm{Cu}^{2+}$ transport in the water-saturated porous media. Column experiments showed that $\mathrm{C}_{60}(\mathrm{OH})_{\mathrm{n}}$ could facilitate the transport of $\mathrm{Cu}^{2+}$. Meanwhile, flow velocity showed little impact on the facilitated transport while $\mathrm{pH}$ and fullerol concentration played an important role. The mechanism of fullerol-facilitated transport of $\mathrm{Cu}^{2+}$ was mainly due to the much higher adsorption capacity of $\mathrm{C}_{60}(\mathrm{OH})_{\mathrm{n}}$ than that of the porous media. Besides, the existence of $\mathrm{C}_{60}(\mathrm{OH})_{n}$ decreased the adsorption kinetics of $\mathrm{Cu}^{2+}$ on the porous media, which led to a decreasing chance for $\mathrm{Cu}^{2+}$ to be retained and thus enhanced the transport of $\mathrm{Cu}^{2+}$.
\end{abstract}

(ㄷ) 2017 Elsevier B.V. All rights reserved.

\footnotetext{
* Corresponding author at: National Engineering Laboratory for Industrial Wastewater Treatment, Research Center for Eco-Environmental Sciences, Chinese Academy of Sciences, Beijing 100085, China.

E-mail address: xjpeng@rcees.ac.cn (X. Peng).
}

\section{Introduction}

With the development of nanotechnology, the application as well as the emission of nanomaterials has increased. Among them, carbon nanomaterials (CNMs), as typical representative model 
compounds for a variety of applications, has been a hotspot of research [1-3]. So far, many studies have been focused on the biotoxicity and biosafety of CNMs in order to assess their environmental risks [4-8]. However, the risks of CNMs in the environment depend not only on their toxicity but also on their environmental behavior including their fate and transport in the environment and their interaction with other environmental contaminants. Therefore, to further understand and more precisely assess the environmental risks of CNMs, it is imperative to study their environmental behavior.

Previous studies have elaborately evaluated the stability and mobility of typical CNMs, e.g. fullerenes, carbon nanotubes (CNTs), graphene and their derivatives [9-13]. During the production and/or utilization process, CNMs could easily obtain high environmental stability by redox reactions and surface complexation, and thus expose and transport for a long distance in environmental media like water, soil and aquifer [14]. Influencing factors such as CNM characteristics [15], $\mathrm{pH}$ and ion strength [16], electrolyte type [17], natural organic matters (NOMs) [18] and surfactants [19] on the stability and mobility of CNMs have also been reported. In addition, CNMs have strong adsorption capability for pollutants in the environment, which may affect the fate and transport of these pollutants. Meanwhile, adsorbed contaminants may increase the hazards of CNM itself too [20]. Thus, it is crucial to study the interaction between CNMs and other contaminants, for instance, the effect of CNMs on the transport of other contaminants.

To date, fullerene nanoparticles $\left(\mathrm{nC}_{60}\right)$ were proved to facilitate the transport of the organic contaminants, e.g. polychlorinated biphenyl (PCB) and phenanthrene, due to the irreversible adsorption and slow desorption kinetics of $\mathrm{nC}_{60}$ for $\mathrm{PCB} /$ phenanthrene [21]. Furthermore, it was found that complexation with surfactants or NOMs could significantly enhance the fullerene-facilitated transport of PCB and the breakthrough of PCB increased substantially after fullerene being complexed with surfactants or NOMs [22]. However, the understanding of the influence of CNMs on heavy metal transport is still limited.

The high stability, mobility and adsorption capability of CNMs may lead to the potentially facilitated transport of heavy metals, and further reduce the retention capacity of heavy metals of media and increase the mobility of heavy metal contaminants, which should arouse more attention and concern. Numerous studies have been conducted to delineate the adsorption ability of CNMs for heavy metal ions in the aqueous environment. For example, studies proved that CNTs have high adsorption capacities for divalent metal ions such as $\mathrm{Cd}^{2+}, \mathrm{Cu}^{2+}, \mathrm{Ni}^{2+}, \mathrm{Pb}^{2+}$ and $\mathrm{Zn}^{2+}$. Besides, the surface oxidation of CNTs remarkably influenced its adsorption capacities for these ions [23]. The mechanism for adsorption of heavy metals on CNMs was mainly the electrostatic attraction, complexation of heavy metal ions with the surface functional groups of CNMs, and the sorption-precipitation [24].

Since the CNMs show a strong adsorption ability for heavy metals, it is reasonable to hypothesize the potentially facilitated transport of heavy metals by CNMs. However, the study on the effect of CNMs on the transport of heavy metals in the porous media is still a lack. Consequently, the primary objective of this research is to study the effect of a typical CNM, i.e., fullerol nanoparticles $\left(\mathrm{C}_{60}(\mathrm{OH})_{n}\right)$, on the transport of $\mathrm{Cu}^{2+}$, one of the typical heavy metal ions, in the porous media, in order to improve the understanding of the environmental risks of CNMs. Based on the study of the stability and mobility of $\mathrm{C}_{60}(\mathrm{OH})_{n}$, whether the average flow velocity, $\mathrm{pH}$, and fullerol concentration would play a role in the potential effect was investigated. Batch adsorption experiments were also conducted to understand the mechanism of the facilitated transport. The results from this study can be regarded as a supplement to obtain a more reliable assessment of the interaction of CNMs with heavy metal contaminants in the aqueous environment.

\section{Experimental}

\subsection{Materials}

Fullerols, which was claimed to have 18-28 hydroxy functional groups by the producer, was purchased from Nanjing XFNANO Materials Tech Co. Ltd (Nanjing, China). It was used as received without further purification. The molecular structure of fullerol was shown in Fig. S1. Quartz sand bought from Beijing Shuangxiangda Instrument Sales Department was used as the porous media. The average particle size of the quartz sand was $523 \mu \mathrm{m}$, which was measured by Laser Diffraction Particle Size Analyzer (Mastersizer 2000, Malvern Instruments Ltd., UK). Before being used, the quartz sand was carefully washed with DI water and dried at $80^{\circ} \mathrm{C}$ for $12 \mathrm{~h}$.

\subsection{Preparation and characterization of fullerol dispersion}

$\mathrm{C}_{60}(\mathrm{OH})_{\mathrm{n}}$ dispersion was prepared by weighing a predetermined amount of $\mathrm{C}_{60}(\mathrm{OH})_{n}$ and adding a prescribed amount of DI water, and then the dispersion was well mixed at $170 \mathrm{rpm}$ under $25^{\circ} \mathrm{C}$ for $6 \mathrm{~h}$. The concentration of $\mathrm{C}_{60}(\mathrm{OH})_{\mathrm{n}}$ dispersion was determined using the UV-vis Spectrophotometer (DR5000, Hach Company, US) at $342 \mathrm{~nm}$ with matched $10 \mathrm{~mm}$ quartz cells. A good correlation between the absorbance and the $\mathrm{C}_{60}(\mathrm{OH})_{n}$ concentration was observed at this wavelength (Fig. S2).

\subsection{Column experiments}

Column experiments were employed to investigate the facilitated transport of $\mathrm{Cu}^{2+}$ by $\mathrm{C}_{60}(\mathrm{OH})_{n}$ in the aqueous environment. Each experiment was replicated for three times, which proved that the results were repeatable. The polymethyl methacrylate (PMMA) columns with a height of $12 \mathrm{~cm}$ and the inner diameter of $3 \mathrm{~cm}$ were employed. Quartz sand was dry-packed into the column at several times. For each time, 1-2 cm height of sand was packed with slight patting on the column side. After that, the porosity of the packed column was measured.

\subsubsection{Transport of fullerol nanoparticles}

The transport of $\mathrm{C}_{60}(\mathrm{OH})_{n}$ in porous media under different average flow velocity $(12 \mathrm{~cm} / \mathrm{h}$ and $60 \mathrm{~cm} / \mathrm{h})$ and different $\mathrm{pH}(5.0$, 6.7 and 7.8) was investigated. Column porosity of these experiments was found to be $0.37 \pm 0.01$. For each experiment, the packed column was firstly loaded with appropriate background solution upward for at least $24 \mathrm{~h}$ at the predetermined flow velocity by a peristaltic pump. The background solution was DI water with the same $\mathrm{pH}$ of the influent and the $\mathrm{pH}$ of all solutions was adjusted by $0.01 \mathrm{M} \mathrm{HCl}$ and/or $0.01 \mathrm{M} \mathrm{NaOH}$ solution. After that, a certain amount of influent solution was loaded into the column upward. The effluent was collected at fixed intervals by a fraction collector (SBS-100, Shanghai Qingpu-Huxi Instruments Factory, China). $\mathrm{C}_{60}(\mathrm{OH})_{n}$ concentrations of influent $\left(\mathrm{C}_{0}\right)$ and of effluent samples (C) were measured and the $C / C_{0}$ values were calculated to plot the breakthrough curve of $\mathrm{C}_{60}(\mathrm{OH})_{\mathrm{n}}$.

\subsubsection{Fullerol-facilitated transport experiments}

To study the fullerol-facilitated transport of $\mathrm{Cu}^{2+}$, the columns were packed and loaded with appropriate background solution as the same way mentioned above. Table 1 gives the experimental protocols of the experiments.

The inert tracer used in these experiments was $\mathrm{Cl}^{-}$, which was prepared by diluting high concentration $\mathrm{NaCl}$ solution to $30 \mathrm{mg} / \mathrm{L}$ $\mathrm{Cl}^{-}$. When the flow velocity and $\mathrm{pH}$ of the column were stable, 
Table 1

Experimental protocols of fullerol-facilitated transport experiments and modeling results of the $\mathrm{Cu}^{2+}$ breakthrough curves.

\begin{tabular}{|c|c|c|c|c|c|c|c|c|c|c|}
\hline \multirow[t]{3}{*}{ Exp. No. } & \multicolumn{3}{|c|}{ Column properties } & \multicolumn{3}{|c|}{ Influent properties } & \multicolumn{4}{|c|}{ Modeling results } \\
\hline & $\rho_{\mathrm{b}}^{\mathrm{a}}$ & $\theta^{\mathrm{b}}$ & $v^{\mathrm{c}}$ & Conc. & Conc. & $\mathrm{pH}$ & $D$ & $R$ & $\beta$ & $\omega$ \\
\hline & $\mathrm{g} / \mathrm{cm}^{3}$ & & $\mathrm{~cm} / \mathrm{h}$ & $\begin{array}{l}\mathrm{Cu}^{2+} \\
\mathrm{mg} / \mathrm{L}\end{array}$ & $\begin{array}{l}\mathrm{C}_{60}(\mathrm{OH})_{\mathrm{n}} \\
\mathrm{mg} / \mathrm{L}\end{array}$ & & $\mathrm{cm}^{2} / \mathrm{h}$ & & & \\
\hline 1 & 1.67 & 0.37 & 58.62 & 9.82 & & 6.7 & 4.48 & 15.43 & 0.60 & 2.24 \\
\hline 2 & 1.70 & 0.36 & 60.36 & 9.95 & 101.5 & 6.7 & 6.70 & 8.30 & 0.24 & 0.57 \\
\hline 3 & 1.66 & 0.37 & 12.36 & 9.91 & & 6.7 & 5.46 & $-d$ & - & - \\
\hline 4 & 1.63 & 0.38 & 11.65 & 9.70 & 99.6 & 6.7 & 4.61 & 8.40 & 0.34 & 0.42 \\
\hline 5 & 1.68 & 0.37 & 59.61 & 10.26 & & 7.8 & 5.85 & - & - & - \\
\hline 6 & 1.66 & 0.37 & 58.68 & 10.60 & 101.7 & 7.8 & 4.85 & 5.42 & 0.38 & 0.51 \\
\hline 7 & 1.69 & 0.36 & 60.06 & 10.61 & & 5.0 & 7.49 & 23.17 & 0.44 & 0.89 \\
\hline 8 & 1.71 & 0.36 & 61.80 & 10.37 & 100.4 & 5.0 & 7.25 & 15.55 & 0.19 & 1.07 \\
\hline 9 & 1.63 & 0.39 & 59.19 & 10.10 & 50.5 & 6.7 & 4.50 & 4.61 & 0.58 & 0.63 \\
\hline 10 & 1.62 & 0.39 & 58.62 & 10.20 & 31.4 & 6.7 & 3.18 & 12.48 & 0.23 & 1.31 \\
\hline
\end{tabular}

a Bulk density of the column.

b Porosity of the column.

c Average flow velocity.

d Since no $\mathrm{Cu}^{2+}$ breakthrough was observed in experiment 3 and 5 , the inverse solution method cannot be used to calculate the parameters $\mathrm{R}, \beta$ and $\omega$.

tracer solution with the same $\mathrm{pH}$ was loaded upward and the effluent was sampled at fixed intervals. Then the $\mathrm{Cl}^{-}$concentration was measured by Ion Chromatography (ICS-1500, Thermo Fisher Scientific Inc., US) and the breakthrough curve of tracer was analyzed for later modeling. After the tracer experiment, the column was flushed with background solution for about $6 \mathrm{~h}$ to eliminate the $\mathrm{NaCl}$ retained in the column.

Before being input to the column, the influent solution with predetermined $\mathrm{Cu}^{2+}$ and $\mathrm{C}_{60}(\mathrm{OH})_{\mathrm{n}}$ concentration were mixed at $170 \mathrm{rpm}$ under $25^{\circ} \mathrm{C}$ for over $24 \mathrm{~h}$ for complete adsorption. After the column being flushed, the influent was input upward and the effluent was collected at fixed intervals. The $\mathrm{Cu}^{2+}$ concentration in the influent $\left(\mathrm{C}_{0}\right)$ and the effluent samples $(\mathrm{C})$ were analyzed by Inductively Coupled Plasma Optical Emission Spectrometer (ICPOES) (ICPE-9800, Shimadzu Corporation, Japan) and the $\mathrm{C}_{60}(\mathrm{OH})_{\mathrm{n}}$ concentration was measured as mentioned above.

Table 1 Experimental protocols of fullerol-facilitated transport experiments and modeling results of the $\mathrm{Cu}^{2+}$ breakthrough curves.

\subsection{Modeling}

The physical non-equilibrium convective-dispersive equation was used to model the $\mathrm{Cu}^{2+}$ transport [25]. In this model, the liquid phase in the porous media was divided into mobile and immobile phases. Solute transport was confined only to the mobile water phase. In the immobile phase, the solute transfer was assumed to be diffusion controlled.

$\beta R \frac{\partial C_{1}}{\partial t}+(1-\beta) R \frac{\partial C_{2}}{\partial t}=\frac{1}{P} \frac{\partial^{2} C_{1}}{\partial x^{2}}-\frac{\partial C_{1}}{\partial x}$

$(1-\beta) R \frac{\partial C_{2}}{\partial t}=\omega\left(C_{1}-C_{2}\right)$

$P=v L / D$

where $C_{1}, C_{2}$ are the solute concentrations of the mobile and immobile water phase, $\beta$ is a dimensionless variable which means the distribution of water in the mobile and immobile phase, $R$ is the retardation factor which represents the extent of retention of solute in the porous media, $D$ is the dispersion coefficient $\left(\mathrm{cm}^{2} / \mathrm{h}\right)$ which is obtained from modeling the tracer experiment, $v$ is the average flow velocity $(\mathrm{cm} / \mathrm{h}), L$ is the transport distance $(\mathrm{cm})$ which equals to the column length in this study, $P$ is Peclet number, $t$ is time and $\omega$ is a dimensionless rate constant. The parameters were simulated by STANMOD program using the inverse solution method.

\subsection{Batch adsorption experiments}

Batch adsorption experiments were conducted to study the mechanism of the facilitated $\mathrm{Cu}^{2+}$ transport by $\mathrm{C}_{60}(\mathrm{OH})_{\mathrm{n}}$. In a typical adsorption isotherm experiment, a certain amount of $\mathrm{Cu}^{2+}$ solution with predetermined concentration were added into a $50 \mathrm{~mL}$ centrifuge tube containing $50 \mathrm{mg} / \mathrm{LC}_{60}(\mathrm{OH})_{\mathrm{n}}$ dispersion or $5 \mathrm{~g}$ quartz sand. The tube was shaken at $25^{\circ} \mathrm{C}, 170 \mathrm{rpm}$ for over $24 \mathrm{~h}$ and then sampled with an injector. In order to remove $\mathrm{C}_{60}(\mathrm{OH})_{n}$, samples containing $\mathrm{C}_{60}(\mathrm{OH})_{\mathrm{n}}$ were filtered using a $3 \mathrm{KD}$ Millipore Ultrafiltration Device centrifuged at $10,000 \mathrm{rpm}$ for $20 \mathrm{~min}$. Other samples were filtered using a $0.22 \mu \mathrm{m}$ PES filter. Then the $\mathrm{Cu}^{2+}$ concentration was measured to calculate the adsorption amount.

In a typical adsorption kinetics experiment, two glass bottles were used, which contain $500 \mathrm{~mL} 10 \mathrm{mg} / \mathrm{L} \mathrm{Cu}^{2+}$ solution, respectively. $50 \mathrm{mg} \mathrm{C}_{60}(\mathrm{OH})_{n}$ was added into one of the bottles and no $\mathrm{C}_{60}(\mathrm{OH})_{\mathrm{n}}$ added into another one. The two bottles were shaken at $25^{\circ} \mathrm{C}, 170 \mathrm{rpm}$ for $24 \mathrm{~h}$ for full adsorption. Then $50 \mathrm{~g}$ quartz sand was added into each bottle respectively, and the bottles were shaken at $25^{\circ} \mathrm{C}, 220 \mathrm{rpm}$. Samples were taken at 0, 5, 10, 30, 60, $120,240,520,1000$, and 1500 min respectively and filtered with $0.22 \mu \mathrm{m}$ PES filters. The $\mathrm{Cu}^{2+}$ concentration was measured to calculate the adsorption amount.

\section{Results and discussion}

\subsection{Stability and mobility of fullerol nanoparticles}

The aqueous stability of $\mathrm{C}_{60}(\mathrm{OH})_{\mathrm{n}}$ dispersion is closely related to its electrokinetic characteristics. Fig. $\mathbf{S} 3$ shows the zeta potential of $\mathrm{C}_{60}(\mathrm{OH})_{\mathrm{n}}$ dispersion as a function of $\mathrm{pH}$. It was shown that $\mathrm{C}_{60}(\mathrm{OH})_{\mathrm{n}}$ are highly negatively charged and its zeta potential ranges from -24.98 to $-37.68 \mathrm{mV}$ in the $\mathrm{pH}$ range of $4.16-9.19$. Under the near-neutral $\mathrm{pH}$ condition, the zeta potential is approximate -30 to $-31 \mathrm{mV}$. In the aqueous environment, zeta potential of $\mathrm{nC}_{60}$ dispersion is from -15.1 to $-29.9 \mathrm{mV}$ in the $\mathrm{pH}$ range of $4.3-9.1$ [10]. Generally, a higher absolute value of zeta potential of a dispersion presents a higher stability in the aqueous environment. This is mainly because that a high zeta potential would provide a high electrostatic repulsion between particles in the liquid phase. Thus the $\mathrm{C}_{60}(\mathrm{OH})_{\mathrm{n}}$ may have higher stability than $\mathrm{nC}_{60}$ in the aqueous environment.

The stability of fullerol dispersion was also investigated using sedimentation test. It can be seen from Fig. S4 that the fullerol dispersion has a considerably high stability since its concentra- 


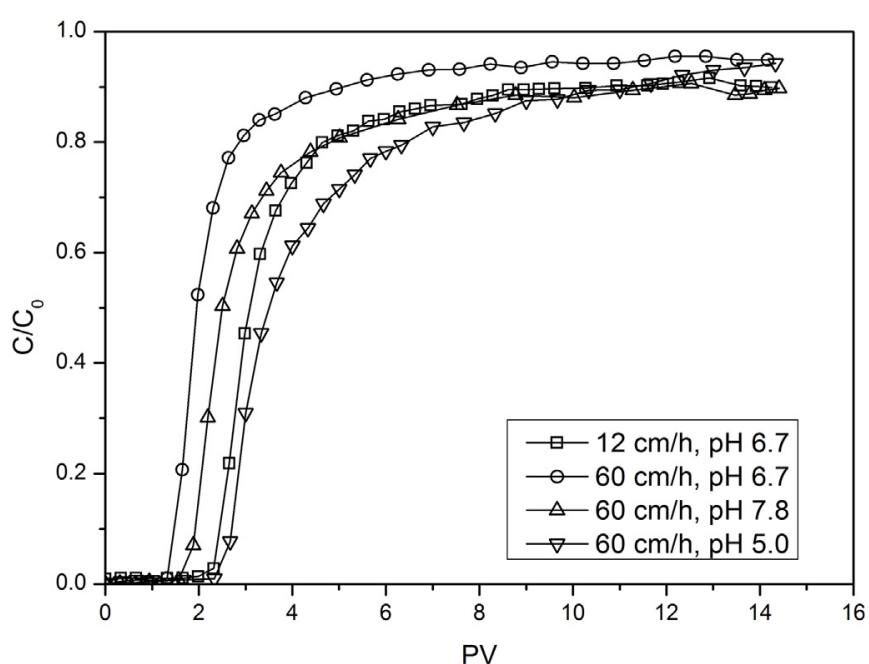

Fig. 1. Breakthrough curves of $\mathrm{C}_{60}(\mathrm{OH})_{\mathrm{n}}$ under different average flow velocities and $\mathrm{pH}$.

tion almost did not change for 30 days. This result proves that the fullerol dispersion has a higher mobility than SWNTs modified by SDS of a low concentration [26], oxidized MWNTs [27], and $\mathrm{nC}_{60}$ colloids [10].

Breakthrough curves of $\mathrm{C}_{60}(\mathrm{OH})_{n}$ in porous media under the condition of different average flow velocity and different $\mathrm{pH}$ are presented in Fig. 1. It could be concluded that $\mathrm{C}_{60}(\mathrm{OH})_{n}$ have significantly high mobility under all conditions investigated in this research since the $C / C_{0}$ value reached over 0.9 within only a few pore volumes $(\mathrm{PV})$.

\subsection{Fullerol-facilitated transport of copper ions}

The column and influent properties are given in Table 1. The effects of three factors, i.e., average flow velocity, $\mathrm{pH}$ and fullerol concentration, were investigated.

\subsubsection{Effect of average flow velocity}

The effect of average flow velocity on the fullerol-facilitated transport of $\mathrm{Cu}^{2+}$ was studied and the results are shown in Fig. 2. Under the condition of both high and low flow velocity, the existence of $\mathrm{C}_{60}(\mathrm{OH})_{n}$ in the influent shows considerable enhancement for $\mathrm{Cu}^{2+}$ transport. When there is no $\mathrm{C}_{60}(\mathrm{OH})_{n}$, the breakthrough of $\mathrm{Cu}^{2+}$ in the porous media is weak and slow and is significantly influenced by flow velocity. Under the high flow velocity, $\mathrm{Cu}^{2+}$ is slightly mobile for the breakthrough curve increases slowly since $8 \mathrm{PV}$ and the $\mathrm{C} / \mathrm{C}_{0}$ value reaches 0.47 at the end of the experiment (over $14 \mathrm{PV}$ ). But when the velocity is relatively low, $\mathrm{Cu}^{2+}$ doesn't show obvious breakthrough within $14 \mathrm{PV}$. The slow velocity gives $\mathrm{Cu}^{2+}$ sufficient time to contact with the surface of the porous media, thus leads to a larger amount of $\mathrm{Cu}^{2+}$ adsorbed on the media surface. However, $\mathrm{C}_{60}(\mathrm{OH})_{n}$ significantly facilitated the $\mathrm{Cu}^{2+}$ transport. Under both fast and slow flow velocities, the breakthrough curves of $\mathrm{Cu}^{2+}$ show a sharp increase in about $2 \mathrm{PV}$, and the $\mathrm{C} / \mathrm{C}_{0}$ values reach about 0.78 at the end of over $14 \mathrm{PV}$. In addition, it is shown in Fig. 2 that the breakthrough of $\mathrm{Cu}^{2+}$ and $\mathrm{C}_{60}(\mathrm{OH})_{n}$ happened simultaneously, which can also be proved by the good linear correlation between $\mathrm{Cu}^{2+}$ and $\mathrm{C}_{60}(\mathrm{OH})_{n}$ concentration (Fig. S4A, B). This phenomenon proves the hypothesis of this research that the $\mathrm{C}_{60}(\mathrm{OH})_{\mathrm{n}}$ could enhance the transport of $\mathrm{Cu}^{2+}$ by carrying $\mathrm{Cu}^{2+}$ to transport through porous media.

CNMs have been proved to enhance the transport of other nanoparticles. For example, the co-transport of nano- $\mathrm{TiO}_{2}$ and $\mathrm{nC}_{60}$ was investigated and it was found that $\mathrm{nC}_{60}$ would enhance the
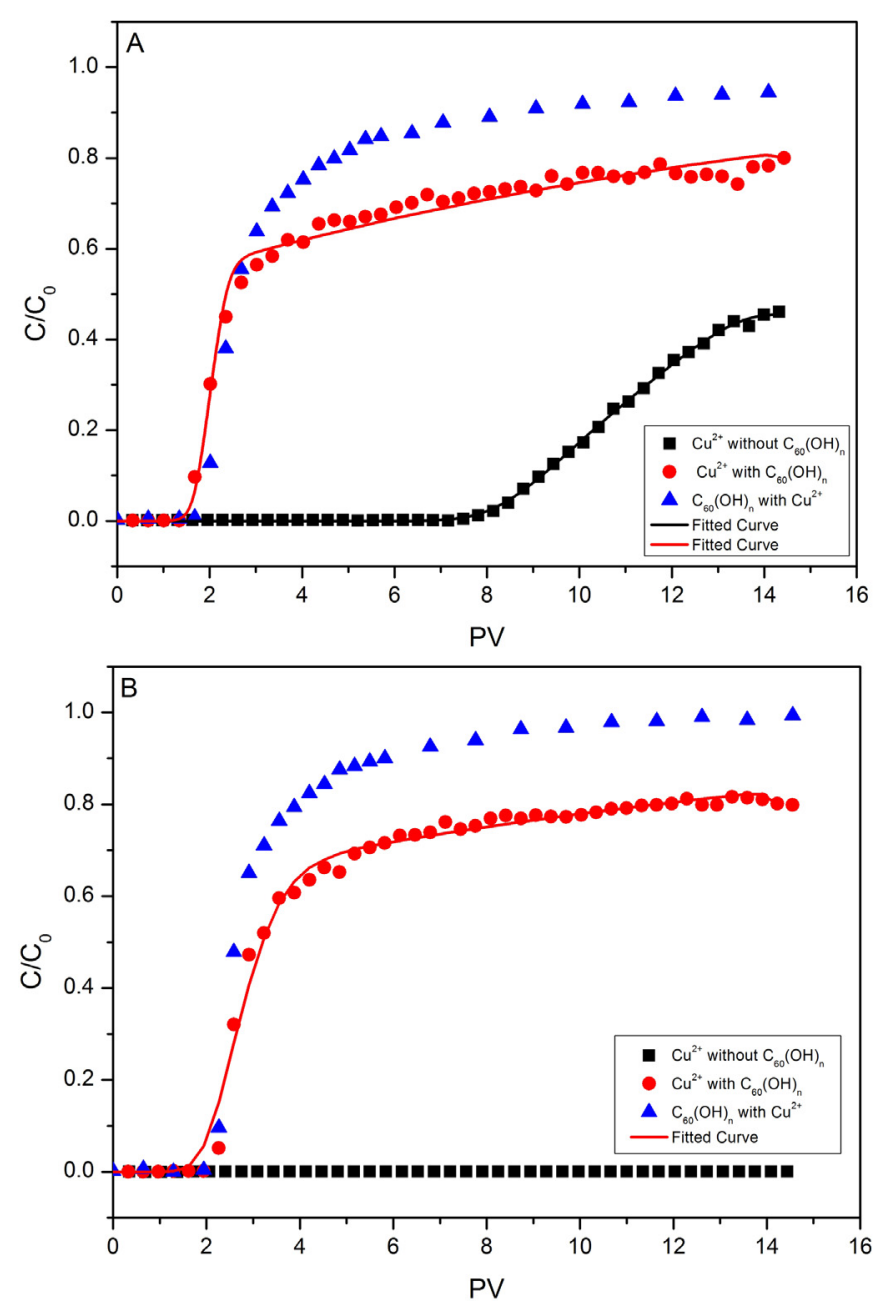

Fig. 2. Breakthrough curves of $\mathrm{Cu}^{2+}$ and $\mathrm{C}_{60}(\mathrm{OH})_{\mathrm{n}}$ in the fullerol-facilitated transport experiments in different flow velocity. A: about $60 \mathrm{~cm} / \mathrm{h}$; B: about $12 \mathrm{~cm} / \mathrm{h}$.

transport rate of nano- $\mathrm{TiO}_{2}$ at $\mathrm{pH} 7$ [28]. Functionalized MWNTs was also presented to enhance nano- $\mathrm{TiO}_{2}$ transport under certain conditions [29]. In these studies, the main mechanism of the enhanced transport is the competition between nano- $\mathrm{TiO}_{2}$ and CNMs ( $\mathrm{nC}_{60}$ and functionalized MWNTs) for deposition sites. However, this could not be the mechanism of the fullerol-facilitated transport of $\mathrm{Cu}^{2+}$ in this study since the $\mathrm{C}_{60}(\mathrm{OH})_{\mathrm{n}}$ transport is almost not influenced by the presence of $\mathrm{Cu}^{2+}$ while in their research, the transport of CNMs was significantly confined by nona- $\mathrm{TiO}_{2}$. It was reported that modified SWNTs could enhance the mobility of gold nanospheres (AuNSs) due to the facilitated transport of AuNSs where the highly mobile PA-SWNTs acted as carriers for the AuNSs. The enhanced transport was attributed to the higher electrostatic attraction between AuNSs and PA-SWNTs than that between AuNSs and sand surfaces [30]. This could also be the reason for the fullerol-facilitated transport of $\mathrm{Cu}^{2+}$ observed in this study since the highly negative charge of $\mathrm{C}_{60}(\mathrm{OH})_{n}$ could effectively attract the positively charged $\mathrm{Cu}^{2+}$ thus may decrease the adsorption of $\mathrm{Cu}^{2+}$ on quartz sand. It was found that $\mathrm{nC}_{60}$ nanoparticles could facilitate the transport of organic contaminants such as polychlorinated biphenyl (PCB) and phenanthrene through sandy soil columns. Similar to this study, results showed that breakthrough of $\mathrm{PCB}$ with $\mathrm{nC}_{60}$ under two different flow velocities were not significantly different. It was concluded that only $\mathrm{nC}_{60}$-absorbed $\mathrm{PCB} /$ phenanthrene can break through the soil column since no breakthrough were found in the single transport 
of $\mathrm{PCB} /$ phenanthrene [21]. However, in this research, $\mathrm{Cu}^{2+}$ still showed some breakthrough from the sand column under high flow velocity. Thus the conclusion obtained from this study should be that the adsorption effect gives $\mathrm{C}_{60}(\mathrm{OH})_{\mathrm{n}}$ great ability to facilitate the transport of $\mathrm{Cu}^{2+}$ in porous media and the effect is more significant under the slow flow velocity.

\subsubsection{Effect of $p H$}

The effect of $\mathrm{pH}$ on the fullerol-facilitated transport of $\mathrm{Cu}^{2+}$ was studied and Fig. 3 presents the results. It is seen that fullerolfacilitated transport of $\mathrm{Cu}^{2+}$ happened under all three $\mathrm{pH}$ conditions However, different from the $\mathrm{C}_{60}(\mathrm{OH})_{n}$ transport shown in Fig. 1, in which $\mathrm{pH}$ shows no obvious influence, both the single $\mathrm{Cu}^{2+}$ transport and fullerol-facilitated $\mathrm{Cu}^{2+}$ transport were affected by $\mathrm{pH}$.

Under the weakly alkaline condition, $\mathrm{Cu}^{2+}$ transport with $\mathrm{C}_{60}(\mathrm{OH})_{\mathrm{n}}$ is enhanced slightly, with a $\mathrm{C} / \mathrm{C}_{0}$ value of 0.89 at over $14 \mathrm{PV}$, while its transport without $\mathrm{C}_{60}(\mathrm{OH})_{n}$ is inhibited and breakthrough of $\mathrm{Cu}^{2+}$ is not observed at $\mathrm{pH}$ 7.8. By contrast, under the weakly acidic condition, $\mathrm{Cu}^{2+}$ transport with $\mathrm{C}_{60}(\mathrm{OH})_{\mathrm{n}}$ decreased considerably at $\mathrm{pH} 5.0$ since the $\mathrm{C} / \mathrm{C}_{0}$ value is only 0.61 after 14 $\mathrm{PV}$, while its transport without $\mathrm{C}_{60}(\mathrm{OH})_{\mathrm{n}}$ is almost the same compared with the neutral condition. One possible explanation is that in the alkaline environment, the dissociation and ionization of surface groups on $\mathrm{C}_{60}(\mathrm{OH})_{\mathrm{n}}$ will become easier, which could increase its adsorption ability for $\mathrm{Cu}^{2+}$ and then facilitate $\mathrm{Cu}^{2+}$ transport. However, in the acidic environment, $\mathrm{C}_{60}(\mathrm{OH})_{\mathrm{n}}$ dissociation and ionization decreased thus the adsorption ability of $\mathrm{C}_{60}(\mathrm{OH})_{n}$ weakened. Besides, the extra $\mathrm{H}^{+}$in the environment is also beneficial for $\mathrm{Cu}^{2+}$ desorption from $\mathrm{C}_{60}(\mathrm{OH})_{\mathrm{n}}$ surface. On the other hand, as is shown in Fig. 3, the transport of $\mathrm{C}_{60}(\mathrm{OH})_{n}$ is slightly enhanced as $\mathrm{pH}$ increased, since the $\mathrm{C} / \mathrm{C}_{0}$ value increased and the breakthrough also happened earlier. Therefore, the fullerol-facilitated transport of $\mathrm{Cu}^{2+}$ would be inevitably improved as $\mathrm{pH}$ increased.

\subsubsection{Effect of fullerol concentration}

The effect of $\mathrm{C}_{60}(\mathrm{OH})_{\mathrm{n}}$ concentration on the fullerol-facilitated transport of $\mathrm{Cu}^{2+}$ was studied and the results are shown in Fig. 4.

It is surprising to find that the enhancement of $\mathrm{Cu}^{2+}$ transport by $\mathrm{C}_{60}(\mathrm{OH})_{n}$ is not entirely positively related to the concentration. It is shown in Fig. $4(\mathrm{~A})$ that a $\mathrm{C}_{60}(\mathrm{OH})_{\mathrm{n}}$ concentration of $31.4 \mathrm{mg} / \mathrm{L}$ has only slight enhancement of $\mathrm{Cu}^{2+}$ breakthrough since the $\mathrm{C} / \mathrm{C}_{0}$ value at $14 \mathrm{PV}$ is almost the same as the $C / C_{0}$ value of single $\mathrm{Cu}^{2+}$ transport. The slight enhancement is reflected by the earlier breakthrough of $\mathrm{Cu}^{2+}$ with $31.4 \mathrm{mg} / \mathrm{LC} \mathrm{C}_{60}(\mathrm{OH})_{\mathrm{n}}$ (starting from $3 \mathrm{PV}$ ) than without $\mathrm{C}_{60}(\mathrm{OH})_{\mathrm{n}}$ (starting from $8 \mathrm{PV}$ ). When the $\mathrm{C}_{60}(\mathrm{OH})_{\mathrm{n}}$ concentration is $50.5 \mathrm{mg} / \mathrm{L}$, the enhancement of $\mathrm{Cu}^{2+}$ transport is the highest with a $C / C_{0}$ value of 0.98 at $14 \mathrm{PV}$. However, when the $\mathrm{C}_{60}(\mathrm{OH})_{\mathrm{n}}$ concentration increased to $101.4 \mathrm{mg} / \mathrm{L}$, the facilitated transport of $\mathrm{Cu}^{2+}$ decreases for a little bit. In Fig. 4(B), it is apparent that the breakthrough curves of $\mathrm{C}_{60}(\mathrm{OH})_{n}$ in corresponding experiments present similar phenomena to $\mathrm{Cu}^{2+}$, where the highest $\mathrm{C} / \mathrm{C}_{0}$ value is found when the $\mathrm{C}_{60}(\mathrm{OH})_{\mathrm{n}}$ concentration is $50.5 \mathrm{mg} / \mathrm{L}$.

It was reported that the increasing $\mathrm{nC}_{60}$ concentration gave rise to a significant increase of PCB breakthrough [21]. However, in this research, the increase of $\mathrm{C}_{60}(\mathrm{OH})_{\mathrm{n}}$ concentration not always leads to the increase of facilitated $\mathrm{Cu}^{2+}$ breakthrough. It can be seen from our results that, when $\mathrm{C}_{60}(\mathrm{OH})_{n}$ concentration increases from 50.5 to $101.4 \mathrm{mg} / \mathrm{L}$, the $\mathrm{Cu}^{2+}$ breakthrough decreases instead. One possible explanation is that aggregation and deposition of $\mathrm{C}_{60}(\mathrm{OH})_{\mathrm{n}}$ were enhanced at a rather high concentration of $101.4 \mathrm{mg} / \mathrm{L}$. To confirm this, the average particle size $\left(\mathrm{Z}_{\mathrm{avg}}\right)$ of $\mathrm{C}_{60}(\mathrm{OH})_{\mathrm{n}}$ nanoparticles in the influent solution of the fullerol-facilitated transport experiments was measured by dynamic light scattering (Zetasizer Nano $\mathrm{ZS}$, UK, Malvern Instruments Ltd.) It is shown that $\mathrm{Z}_{\mathrm{avg}}$ of $\mathrm{C}_{60}(\mathrm{OH})_{\mathrm{n}}$ with concentrations of $50.5 \mathrm{mg} / \mathrm{L}$ and $101.4 \mathrm{mg} / \mathrm{L}$ of $\mathrm{C}_{60}(\mathrm{OH})_{n}$ in
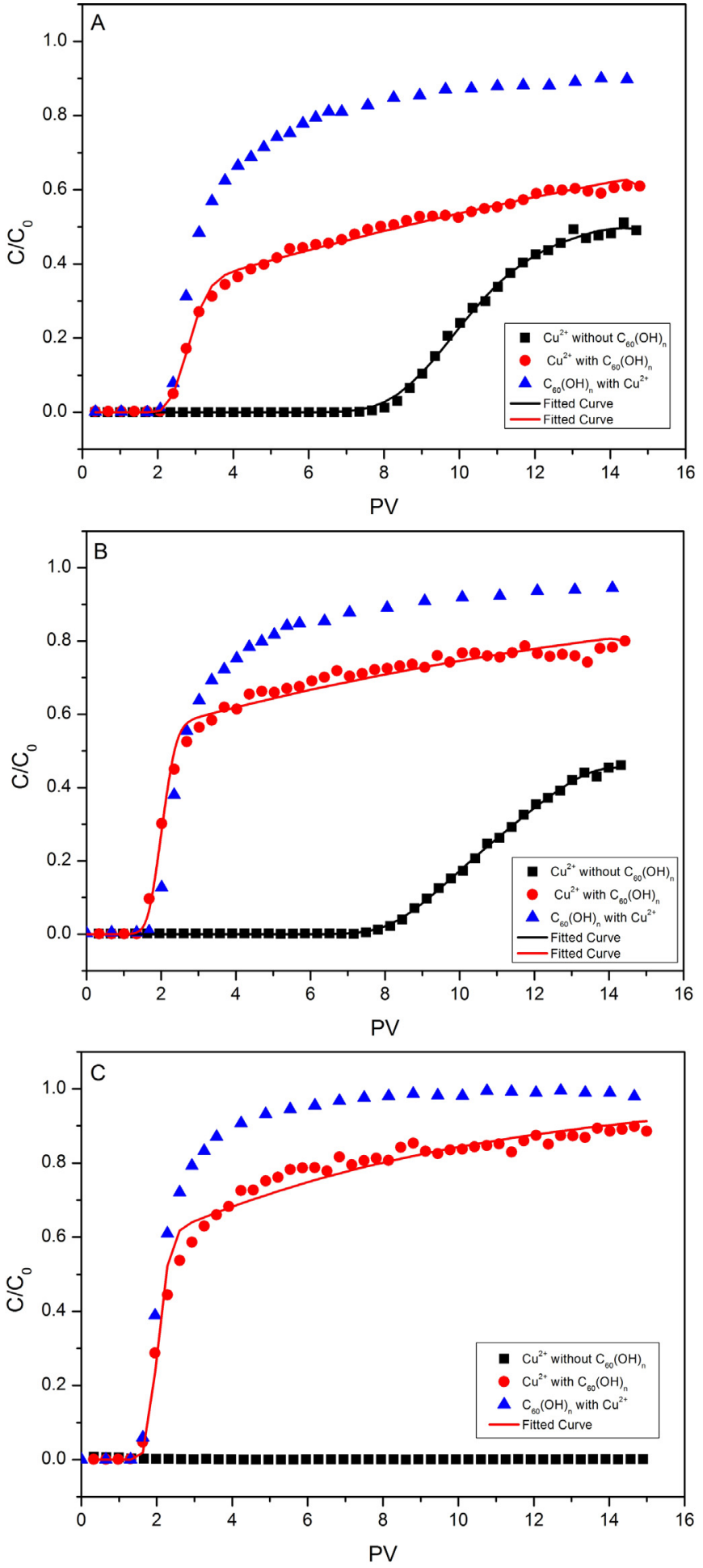

Fig. 3. Breakthrough curves of $\mathrm{Cu}^{2+}$ and $\mathrm{C}_{60}(\mathrm{OH})_{\mathrm{n}}$ in the fullerol-facilitated transport experiments at different pH. A: pH 5.0; $\mathrm{B}$ : pH 6.7.; C: pH 7.8.

$10.2 \mathrm{mg} / \mathrm{LCu}^{2+}$ are $135.3 \mathrm{~nm}$ and $344.7 \mathrm{~nm}$, respectively. This result indicates that much higher aggregation occurs at $\mathrm{C}_{60}(\mathrm{OH})_{\mathrm{n}}$ concentration of $101.4 \mathrm{mg} / \mathrm{L}$ than that at $\mathrm{C}_{60}(\mathrm{OH})_{n}$ concentration of $50.5 \mathrm{mg} / \mathrm{L}$. In fact, it can be seen from Fig. 4(B) that the retention of $\mathrm{C}_{60}(\mathrm{OH})_{\mathrm{n}}$ with a concentration of $101.4 \mathrm{mg} / \mathrm{L}$ increases indeed compared to that with a concentration of $50.5 \mathrm{mg} / \mathrm{L}$, which indicated that the deposition of $\mathrm{C}_{60}(\mathrm{OH})_{\mathrm{n}}$ increases under this concentration. The higher aggregation together with higher deposition of 

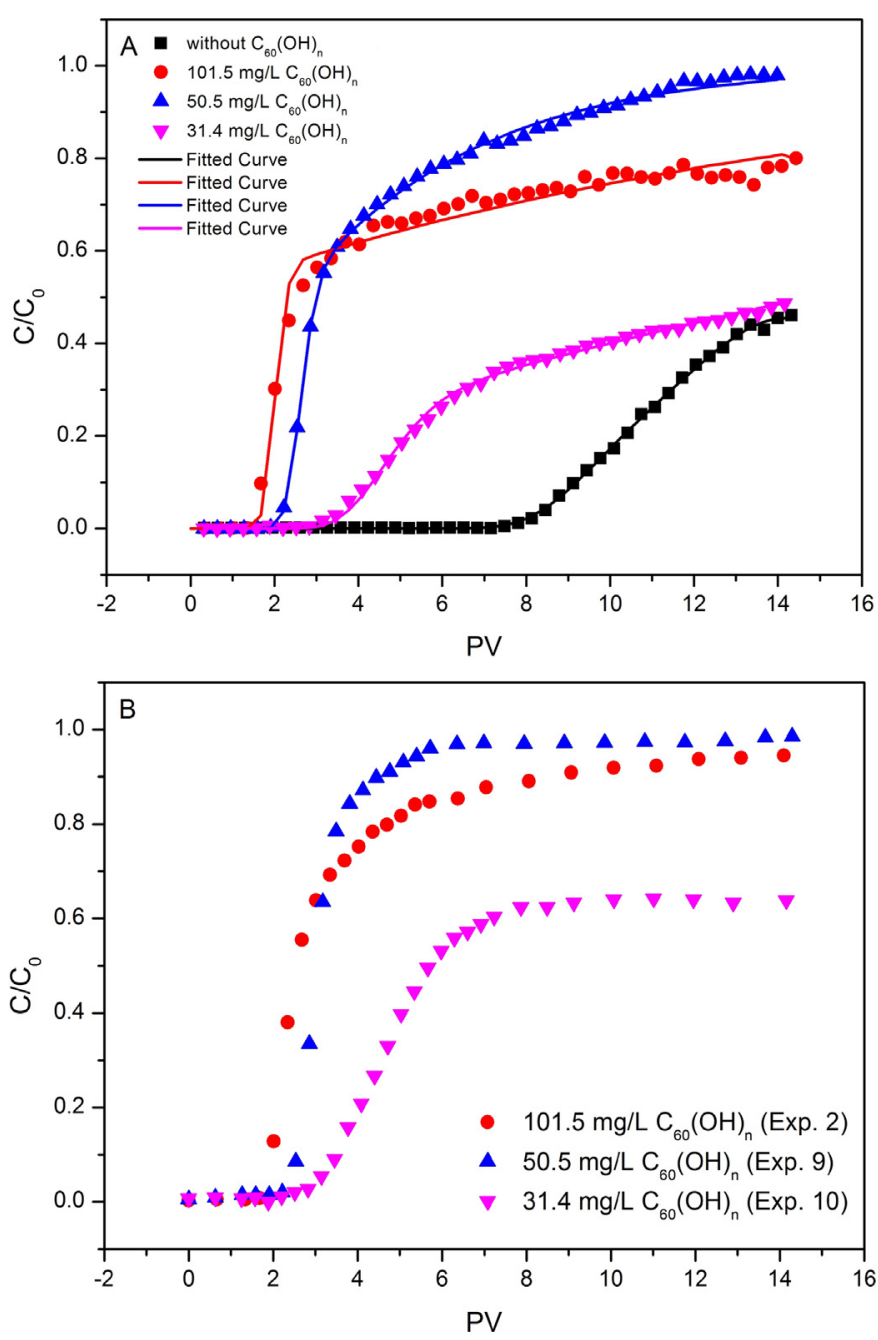

Fig. 4. Breakthrough curves of $\mathrm{Cu}^{2+}(\mathrm{A})$ and $\mathrm{C}_{60}(\mathrm{OH})_{n}(\mathrm{~B})$ in the fullerol-facilitated transport experiments under different $\mathrm{C}_{60}(\mathrm{OH})_{\mathrm{n}}$ concentration.

$\mathrm{C}_{60}(\mathrm{OH})_{\mathrm{n}}$ under $\mathrm{C}_{60}(\mathrm{OH})_{\mathrm{n}}$ concentration of $101.4 \mathrm{mg} / \mathrm{L}$ leads to the decreased breakthrough of $\mathrm{Cu}^{2+}$.

It can be noticed that when $\mathrm{C}_{60}(\mathrm{OH})_{n}$ concentration decrease from $101.5,50.5$ to $31.4 \mathrm{mg} / \mathrm{L}$, the linear relationship between $\mathrm{Cu}^{2+}$ and $\mathrm{C}_{60}(\mathrm{OH})_{\mathrm{n}}$ concentration worsens (Fig. S4A, E, F). When the concentration of $\mathrm{C}_{60}(\mathrm{OH})_{n}$ goes stable, the concentration of $\mathrm{Cu}^{2+}$ is still increasing. This means that under relatively low $\mathrm{C}_{60}(\mathrm{OH})_{n}$ concentration, the breakthrough of free $\mathrm{Cu}^{2+}$ (not absorbed by $\mathrm{C}_{60}(\mathrm{OH})_{n}$ ) counts for a part of the total breakthrough of $\mathrm{Cu}^{2+}$. When the $\mathrm{C}_{60}(\mathrm{OH})_{n}$ concentration is lower, the linear correlation is worse, thus the breakthrough of free $\mathrm{Cu}^{2+}$ plays a more important role in the total $\mathrm{Cu}^{2+}$ breakthrough.

\subsubsection{Modeling results}

It can be seen from the fitted curves in Figs. 2-4 that the experimental data fitted the physical non-equilibrium convectivedispersive equation well. The value of several parameters from modeling results was shown in Table 1.

During all these parameters, the retention factor $R$ is the most important one since it directly reflects how hard it is for solutes to transport in porous media. In this research, it is obvious that the existence of $\mathrm{C}_{60}(\mathrm{OH})_{\mathrm{n}}$ decreases the $R$ for $\mathrm{Cu}^{2+}$ transport. This means that the existence of $\mathrm{C}_{60}(\mathrm{OH})_{n}$ makes the $\mathrm{Cu}^{2+}$ transport in porous media easier. The modeling results are in good agreement with the experimental results and the smallest $R$ value is 4.61 which was found in experiment 9 (with $50.5 \mathrm{mg} / \mathrm{LC}_{60}(\mathrm{OH})_{\mathrm{n}}$ ).

\subsection{Mechanism study}

To further understand the mechanism of fullerol-facilitated $\mathrm{Cu}^{2+}$ transport, batch adsorption experiments were conducted. Fig. 5 shows the Langmuir adsorption isotherms of $\mathrm{C}_{60}(\mathrm{OH})_{n}$ and porous media (quartz sand) on $\mathrm{Cu}^{2+}$ :

$Q=\frac{k C Q_{m}}{1+k C}$

where

$Q, Q_{m}$ are the adsorption amount and the maximum adsorption capability ( $\mathrm{mg} / \mathrm{g})$,

$C$ is the equilibrium concentration $(\mathrm{mg} / \mathrm{L})$, and

$k$ is the Langmuir adsorption equilibrium constant, generally, the higher $k$ value indicated a higher adsorption ability of the adsorbents.

For $\mathrm{C}_{60}(\mathrm{OH})_{\mathrm{n}}$, the maximum adsorption capability is very high with a value of $222.22 \mathrm{mg} / \mathrm{g}$, and the adsorption equilibrium constant is 1.6071 . However, both the two parameters of the porous media have lower values than those of $\mathrm{C}_{60}(\mathrm{OH})_{\mathrm{n}}$. The maximum adsorption capability is only $0.0911 \mathrm{mg} / \mathrm{g}$ and the adsorption equilibrium constant is 0.8828 . These results show that the $\mathrm{C}_{60}(\mathrm{OH})_{n}$ have higher adsorption ability on $\mathrm{Cu}^{2+}$ than the porous media, which means the $\mathrm{Cu}^{2+}$ will be more easily adsorbed by $\mathrm{C}_{60}(\mathrm{OH})_{\mathrm{n}}$
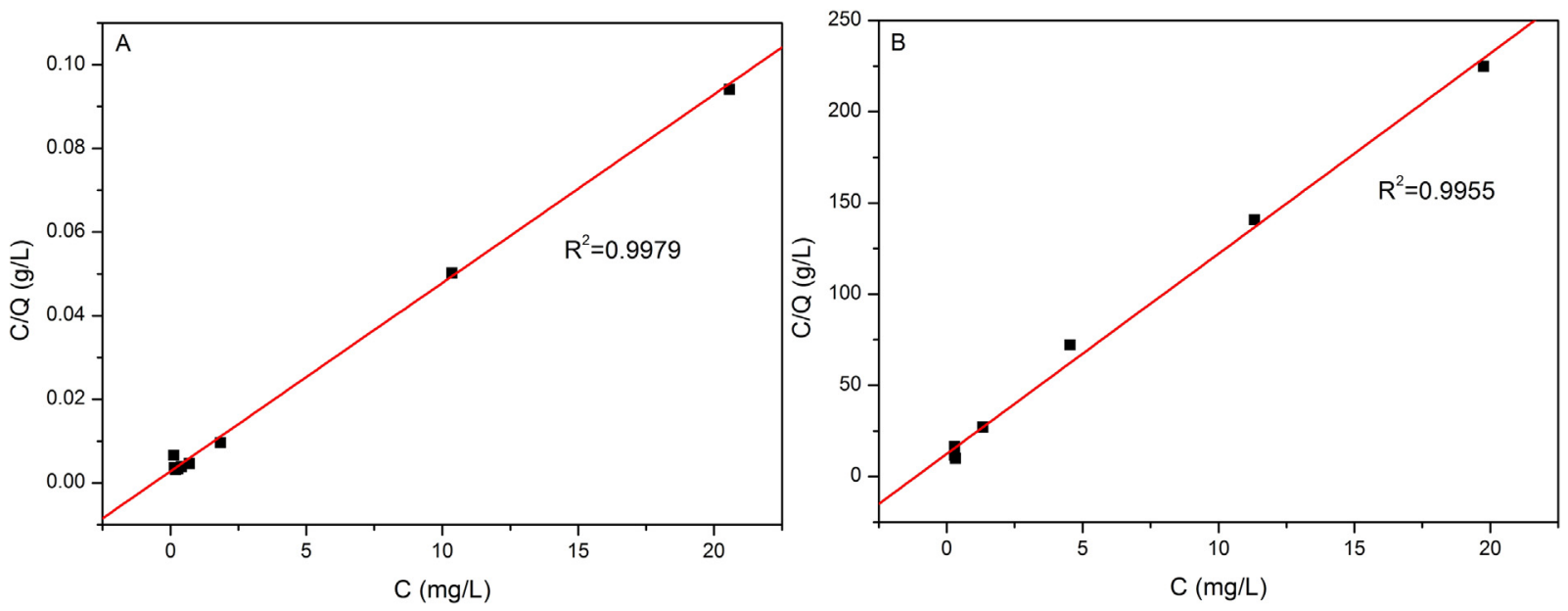

Fig. 5. Langmuir adsorption isotherms of $\mathrm{C}_{60}(\mathrm{OH})_{\mathrm{n}}(\mathrm{A})$ and porous media (B) on $\mathrm{Cu}^{2+}$. 


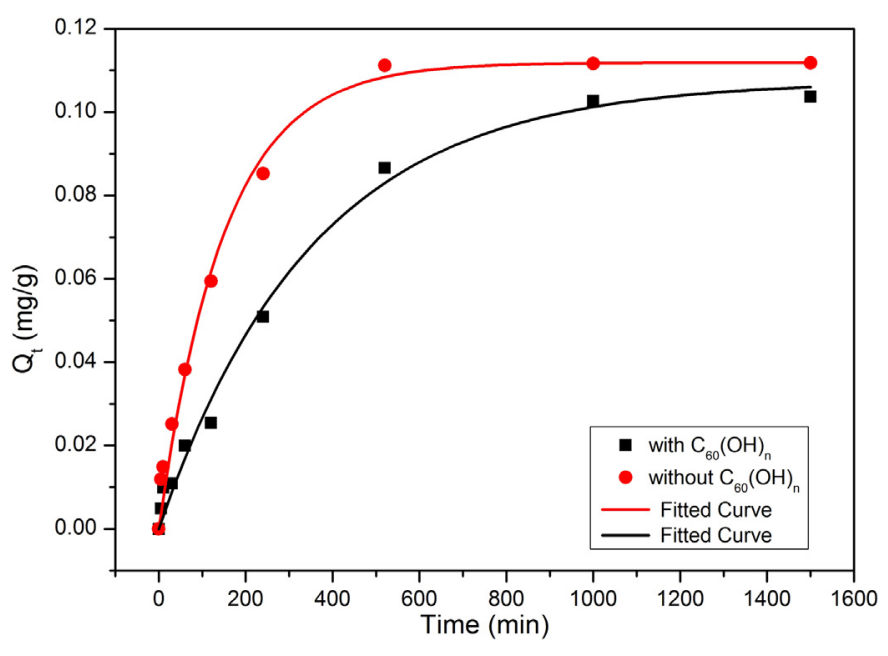

Fig. 6. Effect of $\mathrm{C}_{60}(\mathrm{OH})_{\mathrm{n}}$ on the adsorption kinetics of porous media on $\mathrm{Cu}^{2+}$.

other than by the porous media. Therefore, $\mathrm{Cu}^{2+}$ could be carried by $\mathrm{C}_{60}(\mathrm{OH})_{\mathrm{n}}$ to transport through the porous media.

The effect of $\mathrm{C}_{60}(\mathrm{OH})_{n}$ on the adsorption kinetics of porous media on $\mathrm{Cu}^{2+}$ is shown in Fig. 6. Under the two conditions (with and without $\mathrm{C}_{60}(\mathrm{OH})_{\mathrm{n}}$ ), the adsorption kinetics of $\mathrm{Cu}^{2+}$ on porous media are in accordance with the pseudo-first-order rate equation:

$Q_{t}=Q_{e}\left(1-\mathrm{e}^{-k t}\right)$

where

$Q_{t}$ is the adsorption amount at $t$ time $(\mathrm{mg} / \mathrm{g})$,

$Q_{e}$ is the maximum adsorption capacity $(\mathrm{mg} / \mathrm{g})$, and

$k$ is the pseudo-first-order rate constant.

The maximum adsorption capacity of the porous media for $\mathrm{Cu}^{2+}$ slightly decreased from $0.1119 \mathrm{mg} / \mathrm{g}$ to $0.1075 \mathrm{mg} / \mathrm{g}$ while the rate constant $k$ also decreases from 0.0067 to 0.0028 with the existence of $\mathrm{C}_{60}(\mathrm{OH})_{n}$. It means that with the existence of $\mathrm{C}_{60}(\mathrm{OH})_{\mathrm{n}}$, the rate of $\mathrm{Cu}^{2+}$ adsorption by quartz sand decreases, which implies more time and chance for $\mathrm{Cu}^{2+}$ to transport through the media and then gives rise to the higher mobility of $\mathrm{Cu}^{2+}$. Thus, the existence of $\mathrm{C}_{60}(\mathrm{OH})_{\mathrm{n}}$ can enhance the transport of $\mathrm{Cu}^{2+}$ in porous media.

\section{Conclusions}

In this research, the facilitated transport of $\mathrm{Cu}^{2+}$ by $\mathrm{C}_{60}(\mathrm{OH})_{\mathrm{n}}$ were investigated based on the study of the stability and mobility of the $\mathrm{C}_{60}(\mathrm{OH})_{n}$ dispersion. The following can be concluded.

(1) $\mathrm{C}_{60}(\mathrm{OH})_{\mathrm{n}}$ dispersion had a relatively high stability and mobility in the aqueous environment.

(2) Facilitated transport of $\mathrm{Cu}^{2+}$ by $\mathrm{C}_{60}(\mathrm{OH})_{n}$ were observed. In addition, flow velocity did not remarkably affect the fullerol-facilitated transport of $\mathrm{Cu}^{2+}$ while $\mathrm{pH}$ and $\mathrm{C}_{60}(\mathrm{OH})_{\mathrm{n}}$ concentration influenced it significantly. The breakthrough of $\mathrm{Cu}^{2+}$ fitted the physical non-equilibrium convective-dispersive equation well. Modeling results showed that the presence of $\mathrm{C}_{60}(\mathrm{OH})_{n}$ decreased the retention factor of $\mathrm{Cu}^{2+}$.

(3) The mechanism of $\mathrm{C}_{60}(\mathrm{OH})_{n}$ to facilitate the transport of $\mathrm{Cu}^{2+}$ was mainly due to its much higher adsorption capacity than the porous media. Besides, the existence of $\mathrm{C}_{60}(\mathrm{OH})_{n}$ decreased the adsorption kinetics of the porous media on $\mathrm{Cu}^{2+}$, which led to a decreasing chance for $\mathrm{Cu}^{2+}$ to be retained and thus enhanced the transport of $\mathrm{Cu}^{2+}$.

\section{Acknowledgement}

This work was supported by the National Natural Science Foundation of China (No. 41473113, 41641034).

\section{Appendix A. Supplementary data}

Supplementary data associated with this article can be found, in the online version, at http://dx.doi.org/10.1016/j.jhazmat.2017.07. 001.

\section{References}

[1] S.C. Smith, D.F. Rodrigues, Carbon-based nanomaterials for removal of chemical and biological contaminants from water: a review of mechanisms and applications, Carbon 91 (2015) 122-143.

[2] L. Dai, D.W. Chang, J.B. Baek, W. Lu, Carbon nanomaterials for advanced energy conversion and storage, Small 8 (2012) 1130-1166.

[3] S.F. Oliveira, G. Bisker, N.A. Bakh, S.L. Gibbs, M.P. Landry, M.S. Strano, Protein functionalized carbon nanomaterials for biomedical applications, Carbon 95 (2015) 767-779.

[4] K. Aschberger, H.J. Johnston, V. Stone, R.J. Aitken, C.L. Tran, S.M. Hankin, S.A.K. Peters, F.M. Christensen, Review of fullerene toxicity and exposure -appraisal of a human health risk assessment, based on open literature, Regul. Toxicol. Pharm. 58 (2010) 455-473.

[5] K. Yang, Y. Li, X. Tan, R. Peng, Z. Liu, Behavior and toxicity of graphene and its functionalized derivatives in biological systems, Small 9 (2013) 1492-1503.

[6] Y. Su, J.-Y. Xu, P. Shen, J. Li, L. Wang, Q. Li, W. Li, G.-T. Xu, C. Fan, Q. Huang, Cellular uptake and cytotoxic evaluation of fullerenol in different cell lines, Toxicology 269 (2010) 155-159.

[7] X.Y. Liu, D. Vinson, D. Abt, R.H. Hurt, D.M. Rand, Differential toxicity of carbon nanomaterials in drosophila: larval dietary uptake is benign, but adult exposure causes locomotor impairment and mortality, Environ. Sci. Technol. 43 (2009) 6357-6363.

[8] G.C. Waissi-Leinonen, I. Nybom, K. Pakarinen, J. Akkanen, M.T. Leppanen, J.V. Kukkonen, Fullerenes(nC60) affect the growth and development of the sediment-dwelling invertebrate Chironomus riparius larvae, Environ. Pollut. 206 (2015) 17-23.

[9] H.F. Lecoanet, J.Y. Bottero, M.R. Wiesner, Laboratory assessment of the mobility of nanomaterials in porous media, Environ. Sci. Technol. 38 (2004) 5164-5169.

[10] X. Peng, Y. Yuan, H. Wang, C. Liang, Aqueous stability and mobility of C60 complexed by sodium dodecyl benzene sulfonate surfactant, J. Environ. Sci. 42 (2016) 89-96.

[11] X.J. Peng, C.J. Du, Z. Liang, J. Wang, Z.K. Luan, W.J. Li, Mobility of acid-treated carbon nanotubes in water-saturated porous media, J. Environ. Qual. 40 (2011) 1991-1994.

[12] Y. Li, N. Yang, T. Du, X. Wang, W. Chen, Transformation of graphene oxide by chlorination and chloramination: implications for environmental transport and fate, Water Res. 103 (2016) 416-423.

[13] Y. Qi, T. Xia, Y. Li, L. Duan, W. Chen, Colloidal stability of reduced graphene oxide materials prepared using different reducing agents, Environ. Sci. Nano 3 (2016) 1062-1071

[14] M.R. Wiesner, G.V. Lowry, P. Alvarez, D. Dionysiou, P. Biswas, Assessing the risks of manufactured nanomaterials, Environ. Sci. Technol. 40 (2006) 4336-4345.

[15] Y. Wang, J.-H. Kim, J.-B. Baek, G.W. Miller, K.D. Pennell, Transport behavior of functionalized multi-wall carbon nanotubes in water-saturated quartz sand as a function of tube length, Water Res. 46 (2012) 4521-4531.

[16] L. Liu, B. Gao, L. Wu, V.L. Morales, L. Yang, Z. Zhou, H. Wang, Deposition and transport of graphene oxide in saturated and unsaturated porous media, Chem. Eng. J. 229 (2013) 444-449.

[17] L.L. Zhang, L. Hou, L.L. Wang, A.T. Kan, W. Chen, M.B. Tomson, Transport of fullerene nanoparticles (nC60) in saturated sand and sandy soil: controlling factors and modeling, Environ. Sci. Technol. 46 (2012) 7230-7238.

[18] J. Yang, J.L. Bitter, B.A. Smith, D.H. Fairbrother, W.P. Ball, Transport of oxidized multi-walled carbon nanotubes through silica based porous media: influences of aquatic chemistry, surface chemistry, and natural organic matter, Environ. Sci. Technol. 47 (2013) 14034-14043.

[19] Y.A. Tian, B. Gao, K.J. Ziegler, High mobility of SDBS-dispersed single-walled carbon nanotubes in saturated and unsaturated porous media, J. Hazard. Mater. 186 (2011) 1766-1772.

[20] N. Li, C. Sioutas, A. Cho, D. Schmitz, C. Misra, J. Sempf, M. Wang, T. Oberley, J Froines, A. Nel, Ultrafine particulate pollutants induce oxidative stress and mitochondrial damage, Environ. Health Perspect. 111 (2003) 455-460.

[21] L.L. Zhang, L.L. Wang, P. Zhang, A.T. Kan, W. Chen, M.B. Tomson, Facilitated transport of 2,2',5,5'-polychlorinated biphenyl and phenanthrene by fullerene nanoparticles through Sandy soil columns, Environ. Sci. Technol. 45 (2011) 1341-1348

[22] L. Wang, Y. Huang, A.T. Kan, M.B. Tomson, W. Chen, Enhanced transport of $2,2^{\prime}, 5,5^{\prime}$-polychlorinated biphenyl by natural organic matter (NOM) and 
surfactant-modified fullerene nanoparticles (nC60), Environ. Sci. Technol. 46 (2012) 5422-5429.

[23] G.P. Rao, C. Lu, F. Su, Sorption of divalent metal ions from aqueous solution by carbon nanotubes: a review, Sep. Purif. Technol. 58 (2007) 224-231.

[24] V.K. Gupta, T.A. Saleh, Sorption of pollutants by porous carbon, carbon nanotubes and fullerene- an overview, Environ. Sci. Pollut. Res. 20 (2013) 2828-2843.

[25] M.T. Van Genuchten, Non-Equilibrium Transport Parameters from Miscible Displacement Experiments, 1981.

[26] D. Bouchard, W. Zhang, T. Powell, U.S. Rattanaudompol, Aggregation kinetics and transport of single-walled carbon nanotubes at low surfactant concentrations, Environ. Sci. Technol. 46 (2012) 4458-4465.
[27] X.J. Peng, J.J. Jia, X.M. Gong, Z.K. Luan, B. Fan, Aqueous stability of oxidized carbon nanotubes and the precipitation by salts, J. Hazard. Mater. 165 (2009) 1239-1242.

[28] L. Cai, M. Tong, H. Ma, H. Kim, Cotransport of titanium dioxide and fullerene nanoparticles in saturated porous media, Environ. Sci. Technol. 47 (2013) 5703-5710.

[29] X. Wang, L. Cai, P. Han, D. Lin, H. Kim, M. Tong, Cotransport of multi-walled carbon nanotubes and titanium dioxide nanoparticles in saturated porous media, Environ. Pollut. 195 (2014) 31-38.

[30] A.R.M. Nabiul Afrooz, D. Das, C.J. Murphy, P. Vikesland, N.B. Saleh,

Co-transport of gold nanospheres with single-walled carbon nanotubes in saturated porous media, Water Res. 99 (2016) 7-15. 